\title{
O transplante celular no tratamento da isuficiência cardíaca
}

\author{
Márcio SCORSIN* e Luiz César GUARITA-SOUZA*
}

RBCCV 44205-545

Scorsin M e Guarita-Souza L C - O transplante celular no tratamento da insuficiência cardíaca.

Rev Bras Cir Cardiovasc 2001; 16(3): 183-6.

RESUMO: A insuficiência cardíaca tem sido um grave problema de saúde pública, e provavelmente será a doença cardiovascular predominante neste século. Como a morte dos cardiomiócitos é freqüentemente responsável pelo desenvolvimento da insuficiência cardíaca, uma opção terapêutica de recuperar a função cardíaca é o transplante de células contráteis, principalmente os mioblastos esqueléticos. Os resultados promissores obtidos no âmbito experimental, levou ao primeiro estudo clínico na França, onde mioblastos esqueléticos estão sendo implantados em áreas miocárdicas previamente infartadas, com promissores resultados parciais. Apesar do curto tempo de evolução e do pequeno número de pacientes operados, o transplante celular representa uma opção interessante no arsenal terapêutico da insuficiência cardíaca.

DESCRITORES: Transplante celular, métodos. Baixo débito cardíaco, cirurgia. Miocárdio citologia. Células da medula óssea, transplante. Músculo esquelético, citologia.

\section{INTRODUÇÃO}

Os cardiomiócitos são células altamente diferenciadas e logo após os primeiros anos de vida param de se multiplicar, desta forma, o crescimento do coração é conseqüência da hipertrofia e não a hiperplasia celular. A morte dos cardiomiócitos, por exemplo como conseqüência de um infarto do miocárdio, faz uma fibrose tissular, que dependendo de sua extensão pode levar a insuficiência cardíaca.

A insuficiência cardíaca é um problema de saúde pública com elevados índices anuais de morbi-mortalidade, tanto em países desenvolvidos como em desenvolvimento. $O$ tratamento clínico com os inibidores da enzima de conversão da angiotensina (ECA) e os betabloqueadores, melhoraram o prognóstico dos pacientes sintomáticos, porém o tratamento farmacológico apresenta grandes limitações, sendo o número de pacientes refratários ainda muito alto.

No que diz respeito às opções cirúrgicas, elas vão desde as mais radicais como o transplante cardíaco, até as menos invasivas como o implante de marcapasso biventricular. Existem também várias técnicas que visam a modificação geométrica do coração. A principal desvantagem destes tratamentos é que eles não atuam na causa básica, que é a perda do cardiomiócito.

Entre as novas linhas de pesquisa que visam tratar a insuficiência cardíaca; duas se destacam por atuar na origem do processo patológico. Uma delas, a administração dos fatores angiogênicos, com o intuito de recuperar a vascularização adequada melhorando a perfusão miocárdica, tem se

Trabalho realizado no Hospital Bichat-Claude Bernard. Paris, França. Recebido para publicação em abril de 2001.

* Da Clínica Cardiológyca C. Costantini. Curitiba, PR, Brasil.

Endereço para correspondência: Márcio Scorsin. Rua Pedro Collere, 890.

Vila Isabel, Curitiba, PR, Brasil. CEP:80320-320. Tel: (41) 342-4344. E-mail: mscorsin@hotmail.com 
mostrado muito promissora e com melhora da angina. Paralelamente, o transplante de células musculares no miocárdio fibrosado, com o objetivo de recuperar o seu caráter funcional, tem sido realizado nos últimos sete anos em diferentes modelos experimentais e em diferentes centros de pesquisa no mundo.

Os resultados promissores, relacionado a meIhora da função ventricular, conduziram a realização de um estudo clínico, que está atualmente sendo realizado na França.

O interesse pelo transplante celular surgiu a partir de trabalhos como o de VAN BEKKUM (1), no transplante de medula óssea, de OSTMAN et al. (2) no transplante de ilhotas de Langerhans, de PARTRIDGE et al. (3) com o transplante de mioblasto nos pacientes com distrofia muscular de Duchenne e VELDE et al. (4) com o transplante de células nervosas na terapia de doença de Parkinson.

Os primeiros trabalhos relativos à colonização de células no miocárdio foram encorajadores, tendo sido demonstrado que tanto o miocárdio íntegro como o infartado podem ser colonizados por vários tipos de células contráteis. Várias técnicas de marcação celular foram utilizadas, como a injeção de células contendo o gene da beta-galactosidase, a qual pôde ser identificada no tecido receptor. Outra indicação importante foi a presença das células distrofinapositivas no coração de cães com a doença de Duchenne, que geneticamente não expressam esta proteína, sendo uma evidência ainda maior da capacidade das células colonizarem o músculo nativo. Finalmente, demonstrou-se que os cardiomiócitos fetais foram capazes de sobreviver na zona de transição do infarto com o miocárdio íntegro, abrindo uma perspectiva para colonizar o miocárdio isquêmico(5).

O transplante experimental de células musculares esqueléticas ${ }^{(6)}$, lisas ${ }^{(7)}$, de cardiomiócitos fetais $(5,8)$ e cardiomiócitos adultos ${ }^{(9)}$, no miocárdio infartado, tem sido realizado com o objetivo de determinar qual a célula que apresenta mais vantagens na colonização da área infartada. Entre as principais características que uma célula deve apresentar, o grau de sobrevivência em uma área inóspita é primordial. Apesar de os mecanismos ainda não estarem muito bem definidos, sugere-se que a sobrevida das céIulas transplantadas em plena fibrose pode envolver um possível mecanismo de angiogênese local, induzido pelo próprio transplante das células. Também é preciso lembrar que as células inicialmente não se contraem (pois são imaturas), diminuindo muito a necessidade de energia, permitindo que paralelamente ao desenvolvimento celular também haja o desenvolvimento de uma angiogênese, como demonstrado experimentalmente ${ }^{(10)}$.
Em uma segunda etapa, diferentes estudos foram realizados para se identificar se o transplante celular poderia melhorar a função de um miocárdio comprometido. Uma resposta positiva foi obtida por $\mathrm{Ll}$ et al. (10) que demonstraram, em um modelo de rato com crionecrose miocárdica, que a injeção intramiocárdica de cardiomiócitos fetais aumentou a função global do ventrículo esquerdo após dois meses do transplante, analisando-se pelo método de Langendorff. Ainda utilizando-se o mesmo tipo de célula, estes resultados foram confirmados através de um protocolo ecocardiográfico bidimensional que permitiu visibilizar com mais precisão a melhora da função contrátil do ventrículo esquerdo após o transplante(8).

A vantagem do transplante dos cardiomiócitos fetais é que apresenta a capacidade de integração com os cardiomiócitos nativos, desenvolvendo conexões tipo disco intercalar, facilitando a condução do estímulo elétrico entre as células transplantadas e os cardiomiócitos nativos, fazendo com que as células transplantadas se contraiam sincronicamente, condição fundamental para a melhora da função cardíaca. Entretanto, problemas éticos, relacionados à captação destas células e a necessidade de terapia imunossupressora, são fatores que limitaram a aplicabilidade clínica.

Baseados nos problemas acima mencionados, iniciou-se uma busca por novos tipos de células capazes de melhorar a função miocárdica. Dentre os vários tipos de células estudadas, as células da medula óssea e os mioblastos esqueléticos autólogos parecem ser os mais promissores.

As células da medula óssea contem células progenitoras multipotentes (mesenchymal stem cells), que estão em um estado ainda indiferenciado, mas que apresentam alta capacidade proliferativa. Estudos in vitro demonstram a capacidade de diferenciação destas células em osso, tendão, gordura e músculo. TOMITA et al. ${ }^{(15)}$, em uma cultura celular complexa, junto à 5-azactidina, sugeriram que $30 \%$ destas células podem se diferenciar em cardiomiócitos, com características fetais, apresentando discos intercalares e miotubos. Apesar desta interessante e promissora perspectiva de recuperar a viabilidade miocárdica, a cultura destas células suscita duas questões importantes: é possível cultivar um número suficientemente grande destas células, que possam colonizar a região infartada? Como se trata de uma célula tronco, diferenciada para a linhagem muscular, qual o risco de desenvolver outro tipo de célula no miocárdio, que não o cardiomiócito?

Os mioblastos, que são as células precursoras das fibras musculares esqueléticas, estão presentes em todos os músculos esqueléticos na forma 
hibernante. Elas podem ser ativadas, proliferarem e se diferenciarem em fibra muscular esquelética, a partir de uma agressão física in vivo, ou por meio de cultura celular, in vitro. Foi através dos trabaIhos de MURRY et al. (6) e CHIU et al. ${ }^{(11)}$ que se demonstrou a capacidade de proliferação, diferenciação e colonização destas células, quando transplantadas em corações infartados. TAYLOR et al. (12) obteveram uma importante melhora da função cardíaca, transplantando mioblastos em corações de coelhos criolesados. Em outro estudo realizado (14), comparou-se o transplante de mioblastos esqueléticos e de células cardíacas adultas, no miocárdio infartado. Os resultados mostraram uma limitação da dilatação ventricular esquerda e uma estabilização da fração de ejeção do ventrículo esquerdo no grupo que recebeu células cardíacas, sugerindo um efeito anti-remodelagem. O grupo que recebeu células mioblásticas apresentou acréscimo significativo da fração de ejeção, com preservação da atividade contrátil, entretanto com dilatação ventricular esquerda.

Um estudo determinante para a utilização dos mioblastos esqueléticos como uma das células ideais para este tipo de tratamento foi a comparação funcional com o transplante de cardiomiócitos fetais. Um mês após o transplante em animais previamente infartados, observou-se uma melhora semelhante da fração de ejeção do ventrículo esquerdo entre os dois grupos. Este dado foi extremamente encorajador, pois apesar dos mioblastos não apresentarem os discos intercalares foram capazes de produzir uma melhora funcional muito parecida à obtida pelos os cardiomiócitos fetais.

Após vários anos de estudos experimentais, as autoridades da saúde francesas autorizaram o transplante de mioblastos em humanos, visando nesta primeira fase, apenas a segurança do procedimento. O primeiro paciente a ser beneficiado com este tipo de tratamento recebeu 800 milhões de mioblastos injetados na região inferior do coração, infartada há dois anos (acinesia irreversível, visibilizada pelo ecostress e pela ausência de viabilidade, pelo Pet-scan). Três meses após, observou-se uma recuperação da atividade contrátil na parede inferior com um aumento da fração de ejeção do ventrículo esquerdo de $20 \%$ para $38 \%$. É preciso salientar que foi também realizada a revascularização da parede ânterolateral do ventrículo esquerdo, que provavelmente também foi responsável pela melhora da fração de ejeção. Mas o dado que comprovou a efetividade do procedimento foram dois novos Pet-scan (após dois e quatro meses) que identificaram uma colonização muscular da região previamente infartada (Figuras $1 \mathrm{~A}$ e 1B). Quatro novos pacientes já foram operados, sendo que está prevista uma série de nove pacientes nesta primeira fase do estudo.

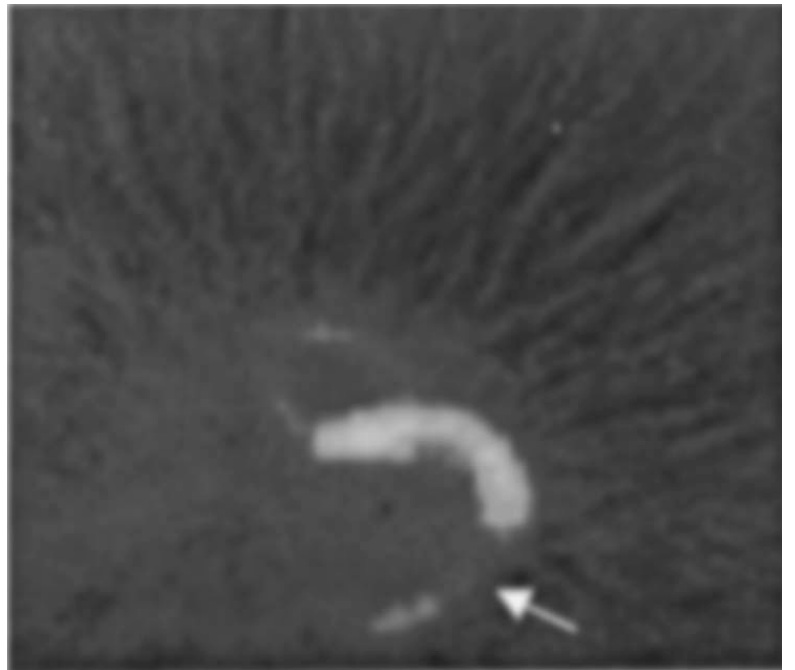

Fig. 1A - Ausência de viabilidade miocárdica na parede inferior do ventrículo esquerdo (Pet-scan).

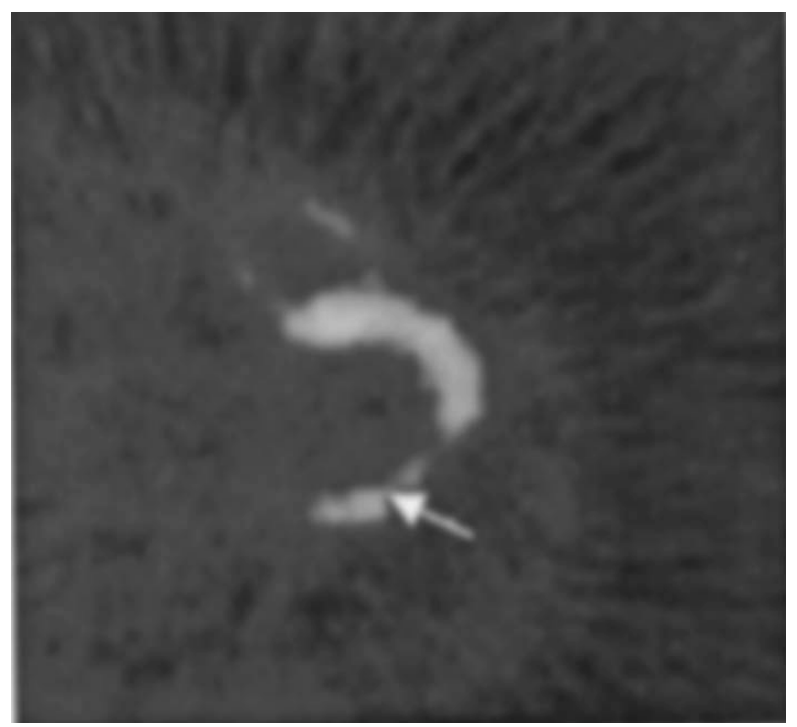

Fig. 1B - Presença de células musculares viáveis na região previamente infartada, após quatro meses do transplante de células mioblásticas esqueléticas (Pet-scan).

Várias dúvidas ainda permanecem com relação ao transplante das células: Existe fadiga das células transplantadas? Qual a durabilidade destas células? Como as células transplantadas podem ser estimuladas, já que não foi identificada a presença dos discos intercalares? Acreditamos que o mais importante é enfatizar a consistência dos estudos experimentais, os quais demonstraram uma melhora da função ventricular pós-transplante. Porém, só um estudo multicêntrico com muitos pacientes poderá determinar qual o lugar exato deste tipo de terapia no tratamento da insuficiência cardíaca. 
Scorsin M \& Guarita-Souza L C - Cell transplantation in the therapy for heart failure. Rev Bras Cir Cardiovasc 2001; 16(3): 183-6.

ABSTRACT: Heart failure is becoming a major problem of public health and it is expected to represent the dominant cardiac disease of this century. Because the death of cardiomyocytes is often responsible for the development of progressive heart failure, cellular transplantation has emerged over recente past years as an attractive alternative therapy. This approach has been stimulated by the recognition in experimental studies that the normal and injured myocardium could be successfully colonized and functionally improved by a variety of contractile cells, mainly skeletal myoblasts. The promising results obtained in an experimental setting triggered the first clinical trial by a French group of myoblast transplantation in previously infarcted myocardium with encouraging preliminary results. Despite the short follow-up and the few patients subjected to this new therapy, cellular transplantation appears as an interesting option in the therapeutic armamentarium for heart failure.

DESCRIPTORS: Cell transplantation, methods. Cardiac output, low, surgery. Myocardium, citology. Bone marrow cells, transplantation. Muscle, skeletal, citology.

\section{REFERÊNCIAS BIBLIOGRÁFICAS}

1 Van Bekkam D W - Present status of bone marrow transplantation following whole body irradiation. Oncology 1966; 20(suppl): 60-72.

2 Ostman J, Lundgreen G, Tydem G, Gunnarsson R, Groth C - Pancreatic transplantation in diabetes mellitus: present status. Acta Endocrinol Suppl (Copenh) 1985; 272: 65-70.

3 Partridge T A, Morgan J E, Coulton G R, Hoffman E P, Kunkel $L$ M - Conversion of $\mathrm{mdx}$ myofibres from dystrophin-negative to positive by injection of normal myoblasts. Nature 1989; 337: 176-9.

4 Velde A A, Bosman D K, Oldenburg J, Sala M, Maas $\mathrm{M}$, Chamuleau $\mathrm{R}$ - Three different hepatocyte transplantation techniques for enzyme deficiency disease and acute hepatic failure. Artif Organs 1992; 16: $522-6$.

5 Scorsin M, Marotte F, Sabri A et al. - Can grafted cardiomyocytes colonize peri-infarct myocardial areas? Circulation 1996; 94(suppl 9): II-337-40.

6 Murry C E, Wiseman R W, Schwartz S M, Hauschka $S$ D - Skeletal myoblast transplantation for repair of myocardial necrosis. J Clin Invest 1996; 98: 2512-23.

7 Li R K, Jia Z Q, Weisel R D, Merante F, Mickley D A - Smooth muscle cell transplantation into myocardial scar tissue improves heart function. J Mol Cell Cardiol 1999; 31: 513-22.

8 Scorsin M, Hagege A A, Marotte F et al. - Does transplantation of cardiomyocytes improve function of infarcted myocardium? Circulation 1997; 96(9 suppl): II-188-93.

9 Sakai T, Li R K, Weisel R D et al. - Autologous heart cell transplantation improves cardiac function after myocardial injury. Ann Thorac Surg 1999; 68: 2074-81.

10 Li R K, Mickle D A, Weisel R D et al. - Natural history of fetal rat cardiomyocytes transplanted into adult rat myocardial scar tissue. Circulation 1997; 96 (9 suppl): 179-87.

11 Chiu R C, Zibaitis A, Kao R L - Cellular cardiomyoplasty: myocardial regeneration with satellite cell implantation. Ann Thorac Surg 1995, 60: 12-8.

12 Taylor D A, Atkins B Z, Hungspreugs $P$ et al. Regenerating functional myocardium: improved performance after skeletal myoblast transplantation. Nat Med 1998; 4: 929-33.

13 Scorsin M, Hagege A, Vilquin J T et al. - Comparison of the effects of fetal cardiomyocyte and skeletal myoblast transplantation on postinfarction left ventricular function. J Thorac Cardiovasc Surg 2000, 119: $1169-75$.

14 Guarita-Souza L C - Transplante de células musculares adultas no infarto do miocárdio: estudo experimental em ratos. [Tese. Doutorado] São Paulo: Faculdade de Ciências Médicas da Santa Casa de São Paulo, 2001.

15 Tomita S, Li R K, Weisel R D et al. - Autologous transplantation of bone marrow cells improves damaged heart function. Circulation 1999; 100:(19 suppl):II247-56. 